Original Research Paper

\title{
The Effect of Using Hysteresis Models (Bilinear and Modified Clough) on Seismic Demands of Single Degree of Freedom Systems
}

\author{
${ }^{1}$ Ahmad N. Tarawneh, ${ }^{2}$ Sereen A. Majdalaweyh and ${ }^{3}$ Bassam Z. Mahasneh \\ ${ }^{1,2}$ Department of Civil Engineering, The University of Jordan, Jordan \\ ${ }^{3}$ Department of Civil Engineering, Mu'tah University, Jordan
}

\author{
Article history \\ Received: 23-02-2016 \\ Revised: 04-08-2016 \\ Accepted: 16-08-2016 \\ Corresponding Author: \\ Ahmad N. Tarawneh \\ and \\ Sereen A. Majdalaweyh \\ Department of Civil \\ Engineering, The University of \\ Jordan, Jordan \\ Email: eng.tarawneh.90@gmail.com; \\ cyrineakram@gmail.com
}

\begin{abstract}
Based on nonlinear inelastic dynamic analysis of Single Degree Of Freedom systems (SDOF), this work investigates the effect of different parameters on the seismic response of these systems. Generalized SDOF systems that present both short and long period structures are subjected to two sets of synthetic ground motions according to the site condition; stiff rock site and stiff soil one, each contains three records. The structural period vary from (0.1 to 2$)$ seconds and the post yielding stiffness ratios vary from (0.0 to 0.2$)$ with two hysteresis models. Modified Clough and Bilinear models have been utilized in the analysis to illustrate the effect of stiffness degradation. The relationship between the force modification factor $(\mathrm{R})$ and the global ductility demand $(\mu)$ tends to be more affected under different post yielding stiffness ratios in the structures of short period more than long period structures, where the effect is negligible. Furthermore, while the post yielding stiffness ratio increases, the ductility demand of the structure decreases under all different periods and models. The effect of hysteresis models at all ranges of period is observed while the modified Clough model shows a higher ductility demand than the force modification factor in comparison with the bilinear model. The site condition influence indicates that short period structures have higher ductility demand in stiff soil sites. However, long period structures have higher ductility demand in stiff rock sites.
\end{abstract}

Keywords: Seismic Response, Synthetic Ground Motions, Hysteresis Model, Post Yielding Stiffness Ratio, Ductility Demand, Force Modification Factor

\section{Introduction}

Designing a structure to remain in the elastic range during earthquake excitation will acquire a very large elastic restoring force to overcome the cyclic action, this large force means large or additional structural elements, which is neither economical nor practical. To avoid that, the design codes permit reducing seismic force by a factor, called force modification factor $(\mathrm{R})$ and in return the design codes allow the structures to undergo inelastic deformations, therefore in that case inelastic analysis will take a place instead of elastic analysis. This permission is conditional, since it is governed by many factors such as ductility, over strength factor, hysteresis behavior of the structure and others. However, the most effective factor is the ductility of the structure, since it controls the amount of inelastic deformations of the structure.
There is no direct defined relationship between the ductility of the structure and the force reduction because this relationship depends on many variables, but generally when the ductility of the structure increases, the reduction of the force increases as well.

Force modification factor $(R)$, presents the amount of reduction in the seismic design force, which is defined as the elastic strength demand $\left(F_{e}\right)$ divided by the inelastic strength demand or the structure yield strength $\left(F_{y}\right)$, force modification factor can be given by Equation 1:

$R=\frac{F_{e}}{F_{y}}$

Global ductility demand ratio $(\mu)$, presents the needed ductility the structure must have to undergo inelastic 
deformations, which is defined as the maximum inelastic displacement $\left(\Delta_{M}\right)$ divided by the structure yield displacement $\left(\Delta_{y}\right)$, global ductility demand ratio can be given by Equation 2:

$\mu=\frac{\Delta_{M}}{\Delta_{y}}$

Earthquakes are characterized by randomness, uncertainty and the participation of many variables in determining the seismic demands of structures, which make the relationship between the force modification factor $(\mathrm{R})$ and the ductility demand $(\mu)$ unpredictable and can be studied only through statistical or probabilistic means.

This work investigates the effect of different parameters on the relationship between the ductility demands $(\mu)$ and the force modification factor $(R)$ and compares the results with one of the previous studies. The different parameters include hysteresis loops, post yielding stiffness ratio, period and site conditions.

Many studies have been conducted to evaluate the effect of different parameters on the seismic demands of the structure, Veletsos and Newmark (1960), have proposed that the lateral peak displacement of moderate and long periods Single Degree Of Freedom (SDOF) systems at elastoplastic behavior have the same elastic lateral peak displacement under the same conditions of period and damping ratio, this is called "Equal displacement rule". On the other hand, the lateral peak displacement of short period SDOF systems at elastoplastic behavior is larger than the elastic peak displacement; this is called "Equal Energy Criteria".

Clough (1966) investigates the effect of stiffness degradation of (SDOF) systems; Clough has found that the seismic demands of stiffness degrading systems are significantly different from stiffness non-degrading systems for short period (SDOF) systems, while it is not the case for long period systems.

Most of the studies have agreed that the elastoplastic system is more conservative for design under earthquake excitation than any other idealization, Riddell and Newmark (1979). However, further studies have been performed to study the effect of stiffness degradation on the seismic response of structures, Nassar and Krawinkler (1991). SDOF systems have been subjected to 16 firm soil ground motions recorded at Whitter Narrow California, with a constant damping ratio. Nassar and Krawinkler have derived an equation in which the response modification factor is a function of ductility demand ratio, post yielding stiffness ratio and the structural period. In addition, Nassar and Krawinkler have found that the response modification factor for stiffness degrading systems is smaller than the response modification factor in stiffness non degrading systems for periods less than $0.4 \mathrm{sec}$. On the other hand, for periods larger than $0.4 \mathrm{sec}$ the response modification factor for stiffness degrading systems are larger than the response modification factor in stiffness non-degrading system. Also, the results have shown that in short period structures there is a large difference in ductility demand ratios between the stiffness degrading and the stiffness non-degrading systems, while in long period structures there is no clear trend.

Several studies were concerned with the influence of the soil condition and hysteresis behavior on the seismic demands of structures, Miranda (2004). Miranda has performed a statistical analysis on generalized (SDOF) systems, subjected to two sets of ground motions; 100 records on soft soils and 16 records on bay mud deposits, with two hysteresis models; elastoplastic model and modified Clough. Miranda has concluded; in short period structures the response modification factor of stiffness degrading systems is larger than the response modification factor of stiffness non-degrading system and smaller for the long period systems.

Ruiz-Garcia and Miranda (2005) examined the effect of hysteresis behavior on 240 ground motions recorded in California. They found that the effect of positive post yielding stiffness ratio is small except in rigid systems.

\section{Earthquake Records}

Six synthetic earthquake records were generated using a program called SeismoArtif, these earthquake records representing two site conditions based on the shear velocity, namely; hard rock and stiff soil. The earthquake records have been normalized to $1 \mathrm{~g}$ in order to provide a common basis for comparison. Figure 1 shows the synthetic records that have been used.

\section{Inelastic Dynamic Analysis}

This study investigates the effect of different parameters on the relationship between $\mathrm{R}$ and $\mu$ for flexible and rigid structures founded on rock and stiff soils. In order to achieve the objectives of the parametric study; an inelastic dynamic analysis is carried out by changing the hysteresis model, post yielding stiffness ratios, structural period, soil condition and the intensity of earthquake excitation. The parameters variation includes; six periods $(0.1,0.2,0.3,0.5,1$ and $2 \mathrm{sec})$, five levels of Peak Ground Acceleration (PGA), four post yielding stiffness ratios $(0,0.05,0.1$ and 0.2$)$, two hysteresis models (Bilinear and modified Clough) and six synthetic records with constant damping ratio of $5 \%$. This variation leads to 1260 pairs of $(R)$ and $(\mu)$ resulted from 1260 inelastic dynamic runs and 720 elastic runs (the zero post yielding stiffness ratio for the modified Clough model has been eliminated). 

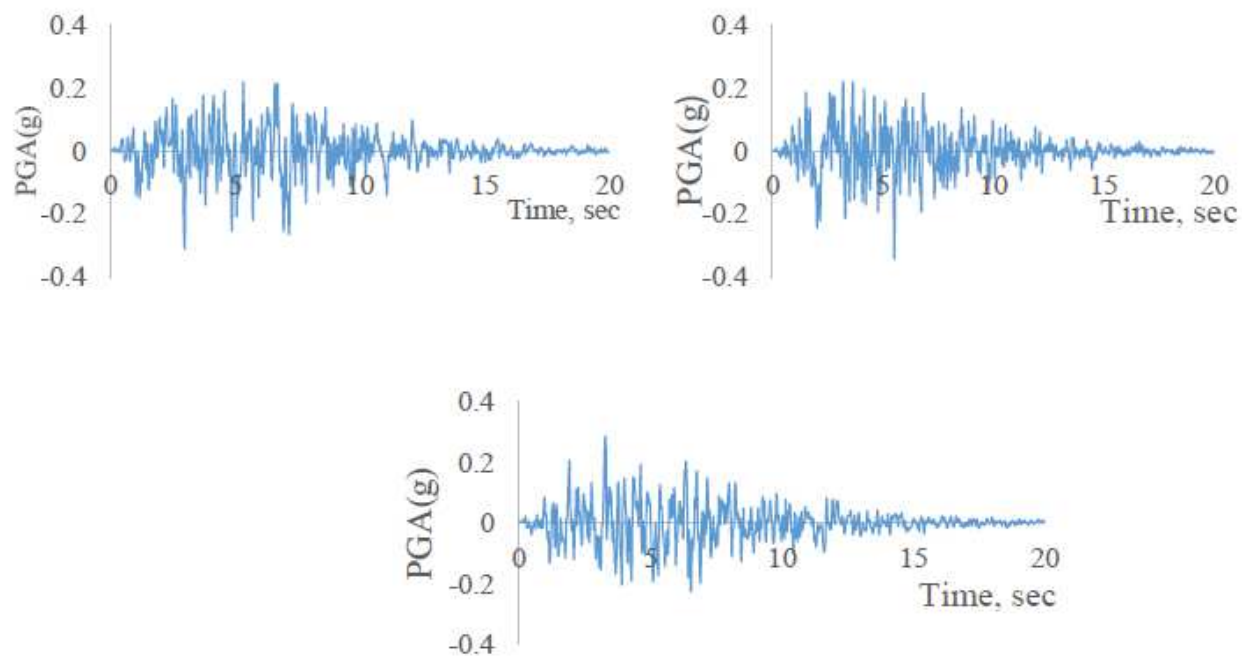

(a)
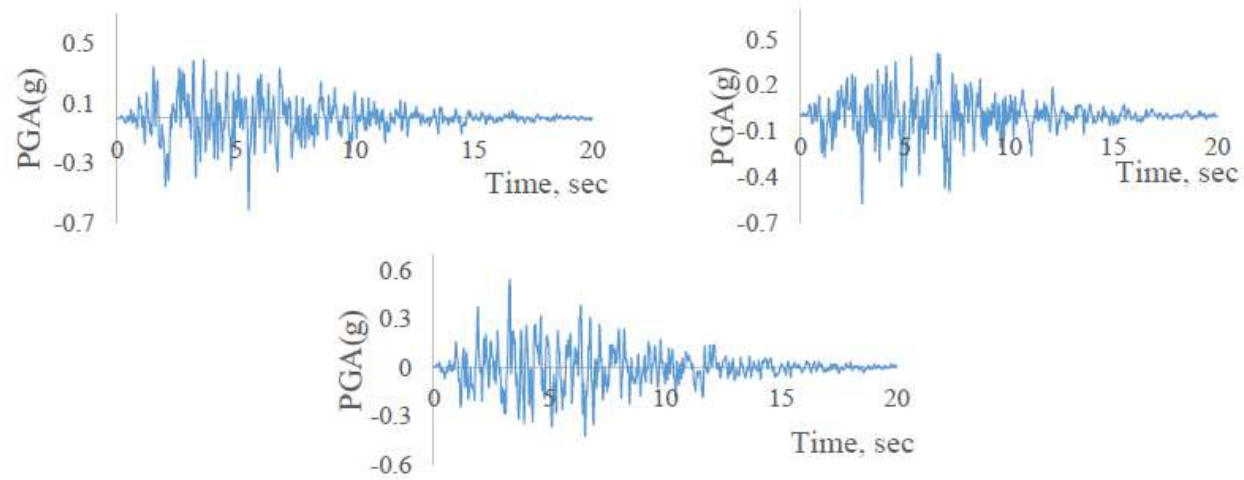

(b)

Fig. 1. Synthetic records used in this work, (a) Hard rock site records, (b) Stiff soil site records

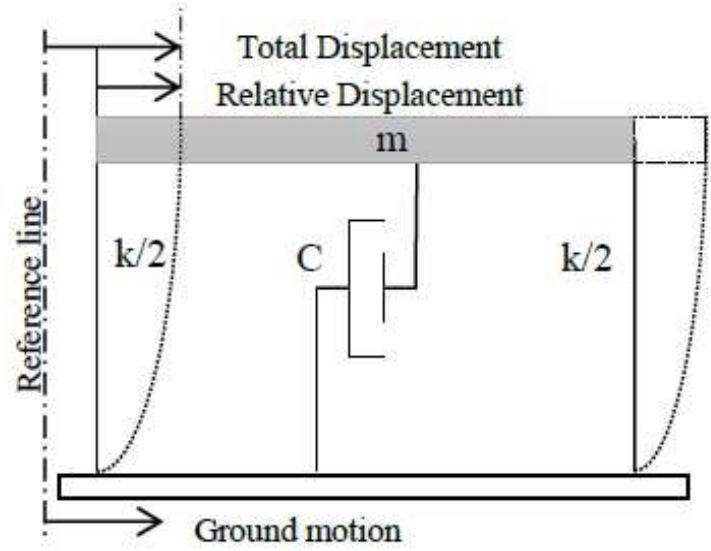

Fig. 2. The generalized SDOF system

The inelastic dynamic analysis is conducted on generalized SDOF systems as shown in Fig. 2, by nonlinear spectral analysis program called Bispec 2.20. The general equation of motion of the generalized SDOF system is given by Equation 3:

$$
m \ddot{u}+c \dot{u}+f_{s}(u)=-m \ddot{u} g(t)
$$

Where:

$\ddot{u} \quad=$ Generalized acceleration, $\left(\mathrm{m} / \mathrm{s}^{2}\right)$

$\dot{u} \quad=$ Generalized velocity, $(\mathrm{m} / \mathrm{s})$

$u=$ Generalized displacement, $(\mathrm{mm})$

$\ddot{u}_{g}(t)=$ Ground acceleration, $\left(\mathrm{m} / \mathrm{s}^{2}\right)$

$m=$ Generalized mass, $\left(\mathrm{kN} . \mathrm{s}^{2} / \mathrm{mm}\right)$

$k=$ Generalized stiffness, $(\mathrm{kN} / \mathrm{mm})$

$\omega=$ the circular frequency $(\mathrm{rad} / \mathrm{s})$

$\zeta=$ the damping ratio of the generalized system

$f_{s}(u)=$ The inelastic restoring force, $(\mathrm{kN})$

The system's inelastic behavior depends basically on the nonlinear relationship between the restoring force and the relative generalized displacement $\left(f_{s}(u)-u\right)$, which is called the hysteretic behavior.

In this study two parameters are utilized into Bispec 2.20. Starting with yielding force of $10 \mathrm{kN}$ (2.248 kips) and yield displacement of $0.01 \mathrm{~m}$ (0.394 in). Several periods 
have been assigned $(0.1,0.2,0.3,0.5,1$ and $2 \mathrm{sec})$, in order to get these desired structural periods $T$, the initial stiffness $k$ is set to be $1000 \mathrm{kN} / \mathrm{m}$ (5.710 kips/in). Then the mass is evaluated at each case using Equation 4:

$$
m=k \cdot\left(\frac{T}{2 \pi}\right)^{2}
$$

In order to find $\mathrm{R}$ and $\mu$, the maximum elastic force $\left(F_{e}\right)$ and the maximum inelastic displacement
$\left(\Delta_{M}\right)$ are required. The yielding level of each single elastic and inelastic dynamic analysis run is kept constant, while the PGA has been modified for each period of time, post yielding stiffness ratio, hysteresis model and ground motion record.

Figure 3 shows a sample of $\mathrm{R}$ and $\mu$ pairs resulted from the procedure described above for 0.2 post yielding stiffness ratio. As shown from the Figure, the relationship between $\mathrm{R}$ and $\mu$ is scattered and does not have any direct trend.

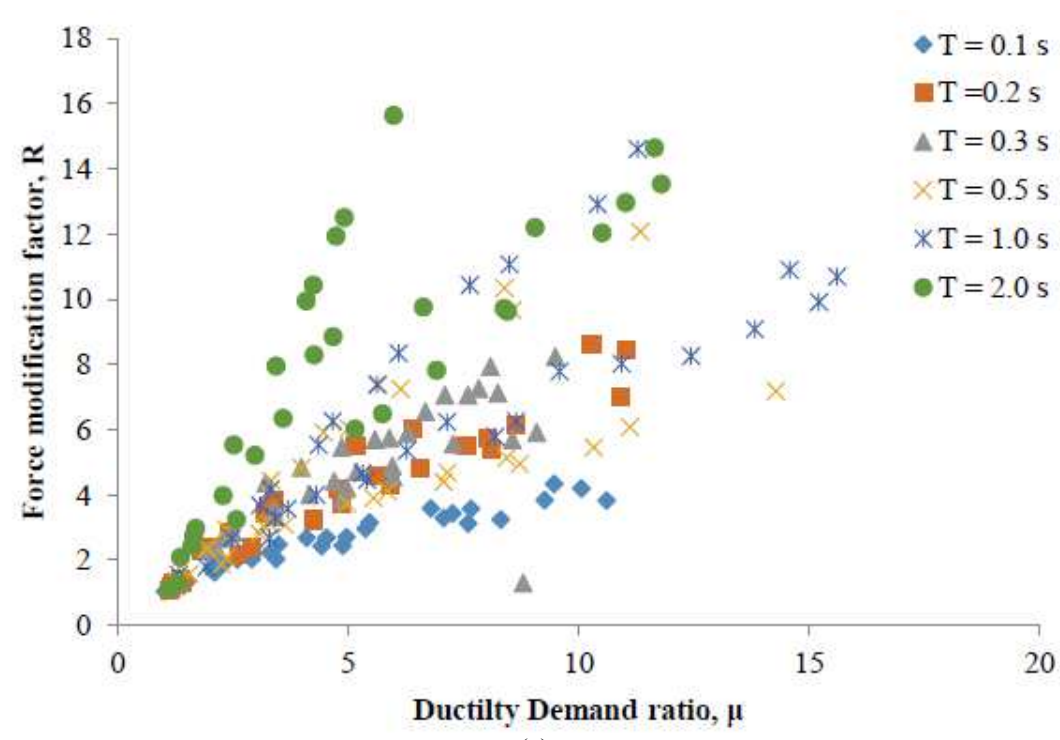

(a)

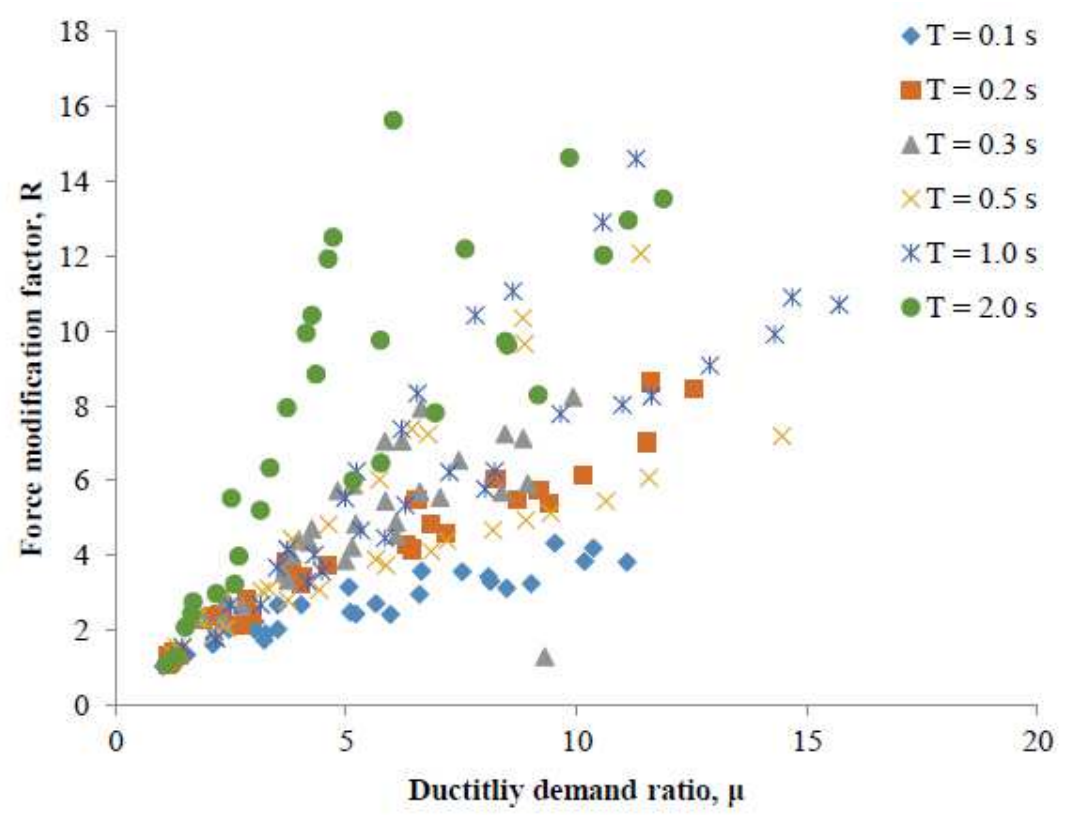

(b)

Fig. 3. R- $\mu$ relationship for both models at 0.2 post yielding stiffness ratio under the excitation of all synthetic records, (a) R- $\mu$ relationship for bilinear model, (b) R- $\mu$ relationship for clough model 


\section{Hysteresis Models}

The response of the structure could be presented by displacement history or hysteresis model. In this study two hysteresis models are used, namely; bilinear and modified Clough. Their characteristics are shown in (Fig. 4).

Figure $4 \mathrm{a}$, presents properly the properties of the bilinear model, while the yielding strength remains constant under the cyclic loading, in addition that the model does not show any stiffness degradation or strength deterioration. The ratio between the post yielding stiffness to the initial stiffness in the model is called "Post Yielding Stiffness Ratio".

Figure 4b, shows the modified Clough model properties. The most important point in this model is its stiffness degradation while it makes it more representative of reinforced concrete buildings.

In Bispec 2.20 the model type can be chosen easily with its desired post yielding stiffness ratios, a sample of the results for all post yielding stiffness ratios are displayed in (Fig. 5 and 6). These figures illustrate how the post yielding stiffness ratio affects the maximum displacement and maximum restoring force of SDOF systems, as well as the post yielding stiffness ratio effect on the size of the loop, while it gets narrower when the post yielding stiffness ratio raises for both models and that means as long as the post yielding ratio increases the hysteretic energy dissipation capacity decreases.

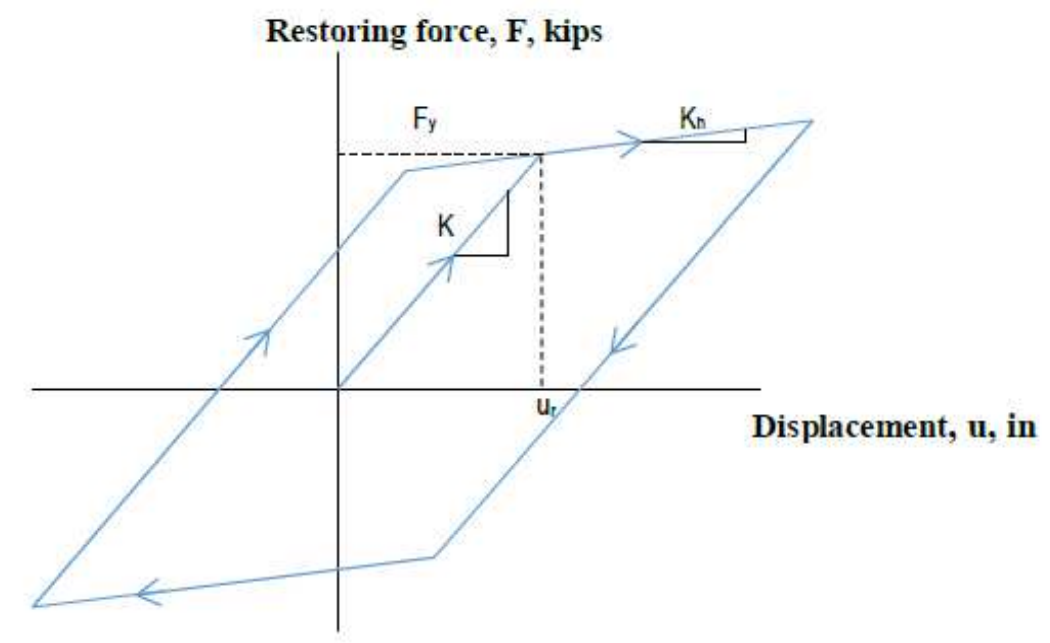

(a)

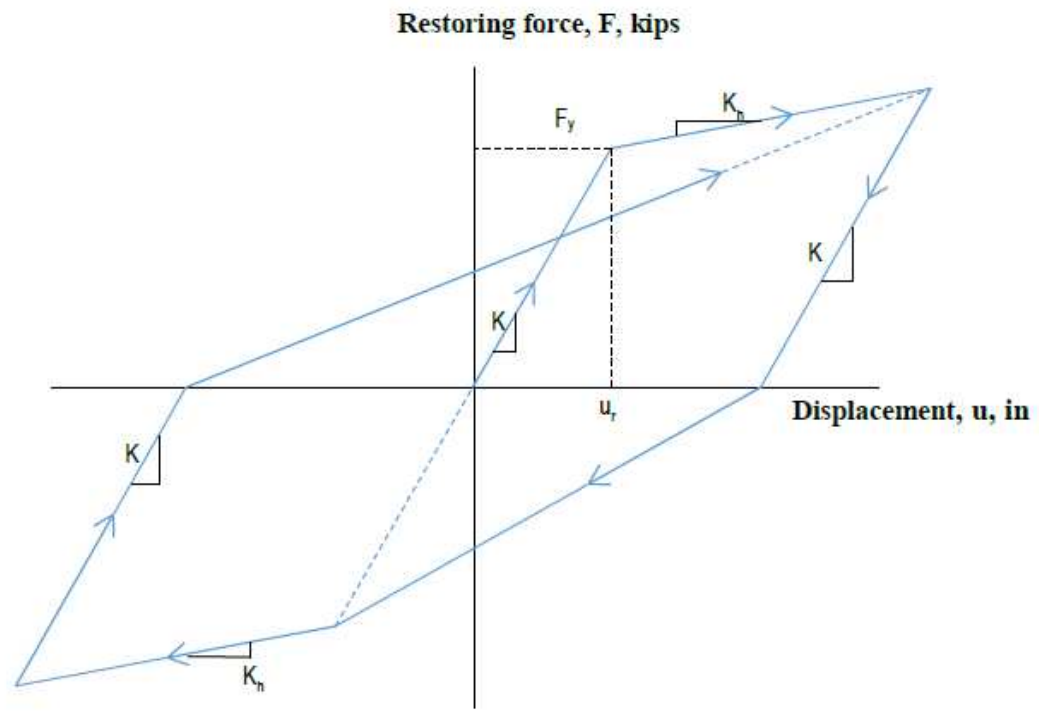

(b)

Fig. 4. Hysteresis models used in the study, (a) Bilinear hysteresis model, (b) Modified clough model 


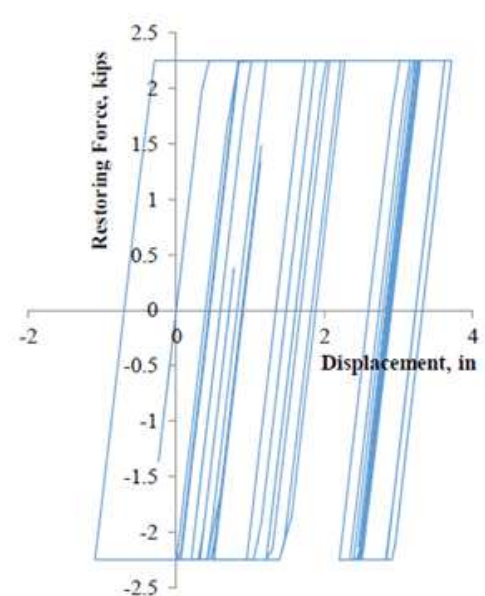

(a)

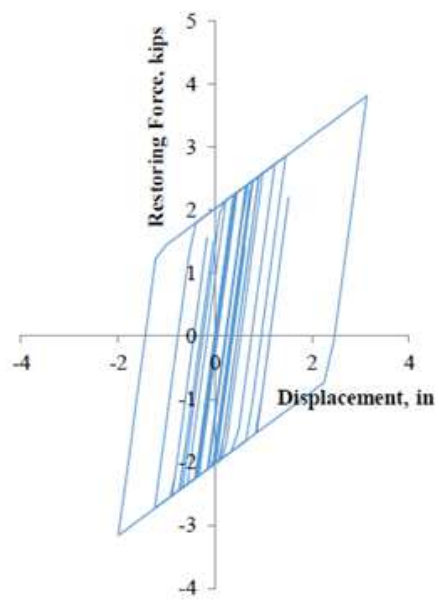

(c)

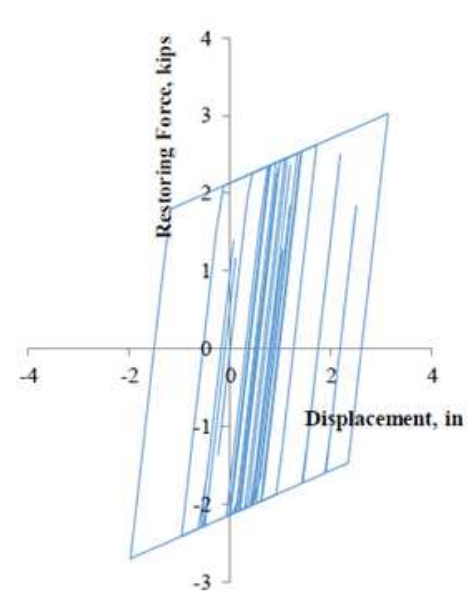

(b)

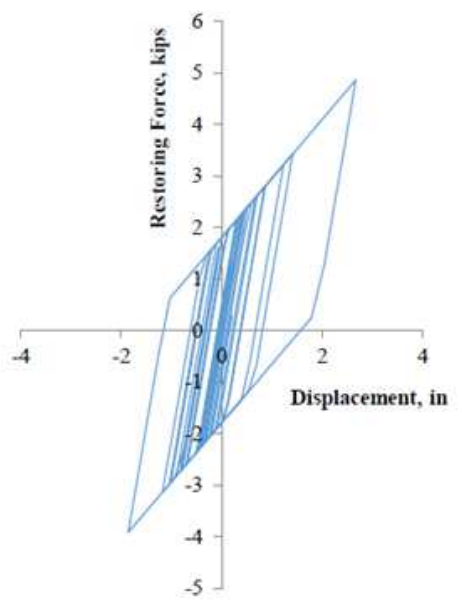

(d)

Fig. 5. Bilinear hysteresis model for all post yielding stiffness subjected to stiff soil record for period 1 second, (a) Post yielding stiffness ratio $0 \%$, (b) Post yielding stiffness ratio 5\%, (c) Post yielding stiffness ratio 10\%, (d) Post yielding stiffness ratio 20\%

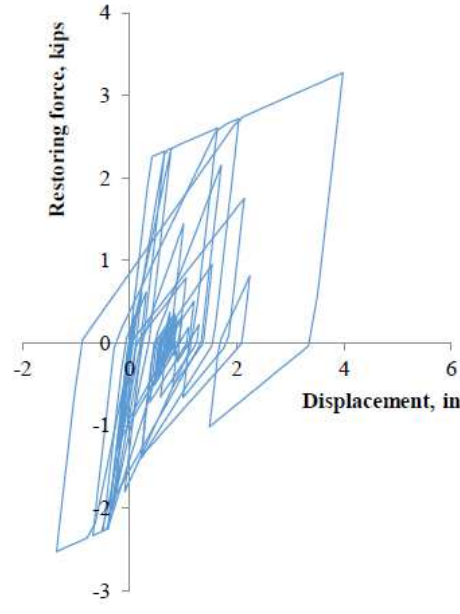

(a)

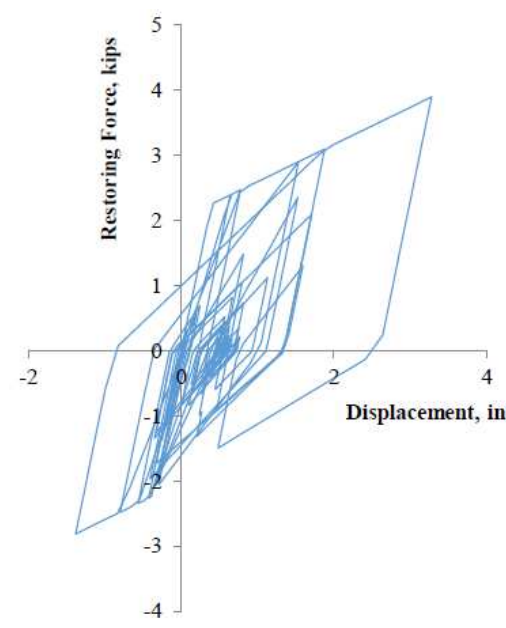

(b)

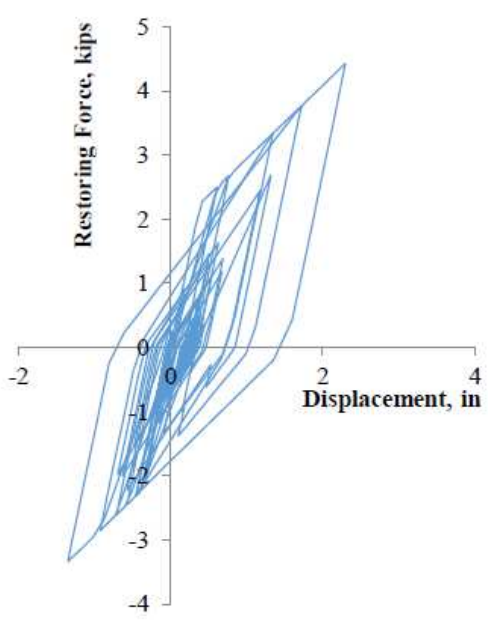

(c)

Fig. 6. Clough hysteresis model for all post yielding stiffness subjected to hard rock record for period 1 second, (a) Post yielding stiffness ratio 5\%, (b) Post yielding stiffness ratio 10\%, (c) Post yielding stiffness ratio $20 \%$ 


\section{Nassar and Krawinkler Model}

Nassar and Krawinkler (N\&K) did a comprehensive study on SDOF systems with typical damping ratio $5 \%, N \& \mathrm{~K}$ have proposed a general form that relates $\mathrm{R}, \mu$ and the structural period, as indicated in Equation 5 and 6:

$$
\begin{aligned}
& R=[C(\mu-1)+1]^{\frac{1}{C}} \\
& C=\frac{T^{a}}{1+T^{a}}+\frac{b}{T}
\end{aligned}
$$

where, $C$ is nonlinear regression parameter, $a$ and $b$ are nonlinear regression constants depends on the post yielding stiffness ratio of the bilinear model.

Figure 7 shows a plot of $C$ versus the period $T$, for three post yielding stiffness ratios which designated as PY; 0.0, 0.02 and 0.1 . This figure will be the reference for the analysis of this work and the values of $a$ and $b$ used in these plots are tabulated in Table 1.

From Fig. 7 it could be noticed that for long period systems, C become almost constant, while for short period systems $\mathrm{C}$ is larger and shows more variability. C parameter is related to seismic demand of the structure; when $\mathrm{C}$ is higher the ductility demand ratio $\mu$ is larger than the force modification factor and when $\mathrm{C}$ is lower the ductility demand ratio is lower than the response modification factor.

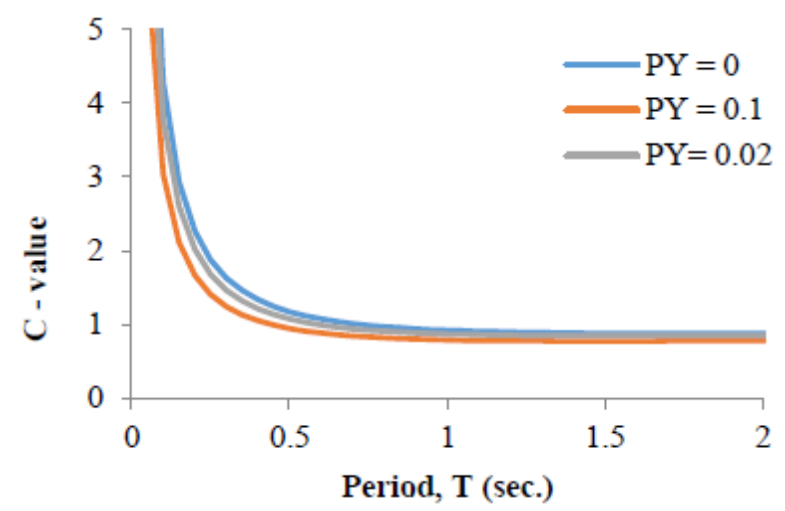

Fig. 7. Relationship between parameter $\mathrm{C}$ and the period $\mathrm{T}$ according to (N\&K) model

Table 1. The parameter $\mathrm{C}$ values

\begin{tabular}{lll}
\hline $\begin{array}{l}\text { Post yielding } \\
\text { stiffness ratio }\end{array}$ & $\mathrm{a}$ & $\mathrm{b}$ \\
\hline 0 & 1.0 & 0.42 \\
0.02 & 1.0 & 0.37 \\
0.1 & 0.8 & 0.29 \\
\hline
\end{tabular}

\section{Results and Discussion}

When $\mathrm{R}$ and $\mu$ data base is completed, (N\&K) model parameter $\mathrm{C}$ is evaluated by nonlinear regression analysis using MATLAB R2012a (2012). The parameter $\mathrm{C}$ is found for each period, hysteresis model and soil condition. Then it is compared with the (N\&K) model.

Figure 8 shows a sample of nonlinear regression curve to determine parameter $\mathrm{C}$ for period of $0.1 \mathrm{sec}$. The used modified Clough model was with $10 \%$ post yielding stiffness ratio and subjected to both site condition records. The parameter $\mathrm{C}$ value is equal to 2.413. The other values of parameter $\mathrm{C}$ for all records are tabulated in Table 2 and 3.

Figure 9 and 10 illustrate the differences between $(\mathrm{N} \& \mathrm{~K})$ model of zero post yielding stiffness ratio and the obtained C-values.

It could be noticed from the (Fig. 9 and 10) that as post yielding stiffness ratio increases the $\mathrm{C}$-values decreases; which indicates a lower ductility demand ratio. When the post yielding stiffness ratio increases the maximum restoring force of SDOF systems will increase and the maximum inelastic displacement of the SDOF systems will decrease which leads to a ductility demand ratio lower than the force modification factor that indicates to a lower $\mathrm{C}$-values. It should be mentioned that, the effect of post yielding stiffness ratio decreases as the period increases; it can be noticed from the small differences between the $\mathrm{C}$-values, because the ductility demand of long period systems (flexible systems) is small. Therefore, rigid structures are sensitively affected by post yielding stiffness ratio.

Figure 11 demonstrates the difference between the bilinear model and the modified Clough model, as it is obvious that the modified Clough model has the slightly larger $\mathrm{C}$-values than the bilinear almost in all cases, which means; the ductility demand of the modified Clough model is higher than the bilinear model.

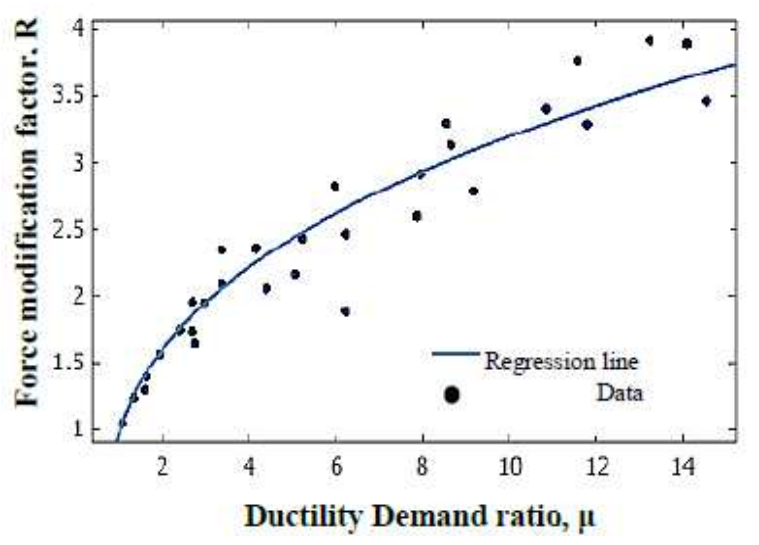

Fig. 8. Sample of nonlinear regression curve 


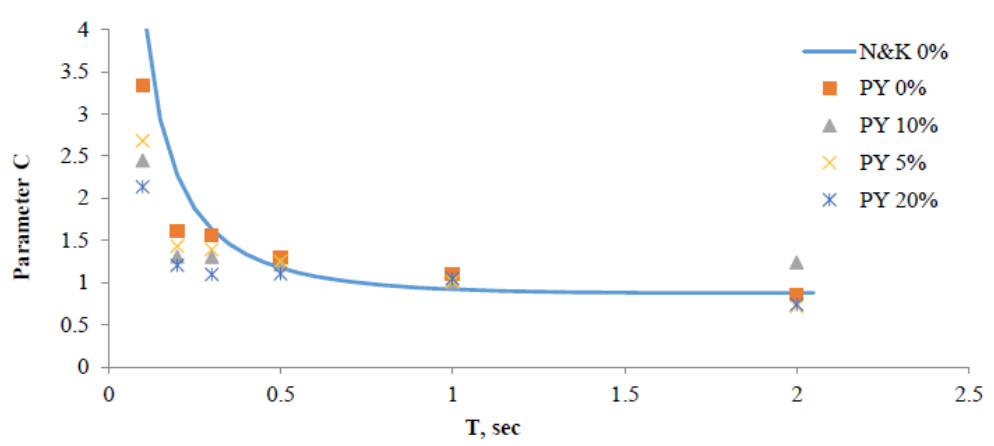

Fig. 9. Values of parameter $\mathrm{C}$ for Bilinear model at different periods against $(\mathrm{N} \& \mathrm{~K})$ model

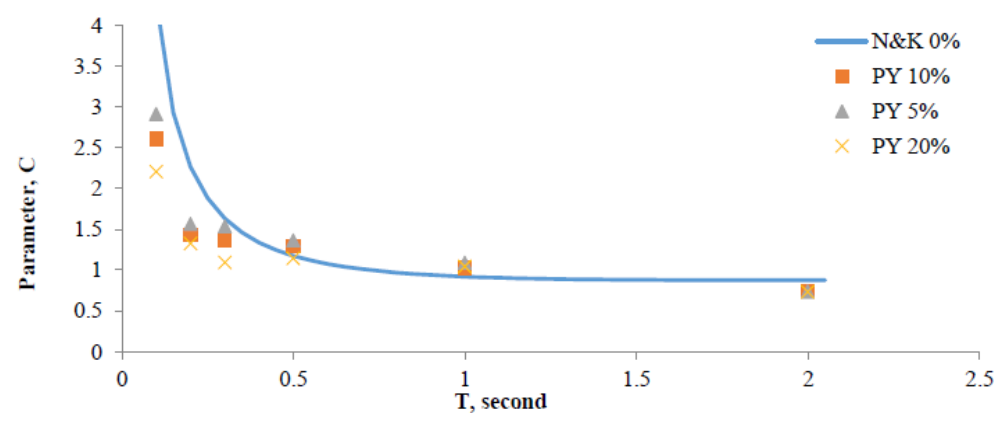

Fig. 10. Values of parameter $\mathrm{C}$ for modified Clough model at different periods against (N\&K) model

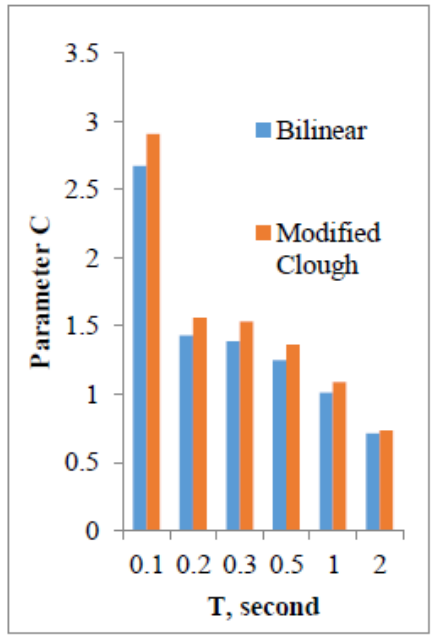

(a)

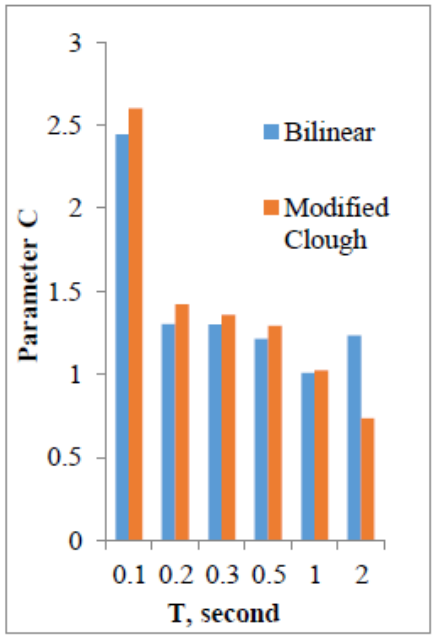

(b)

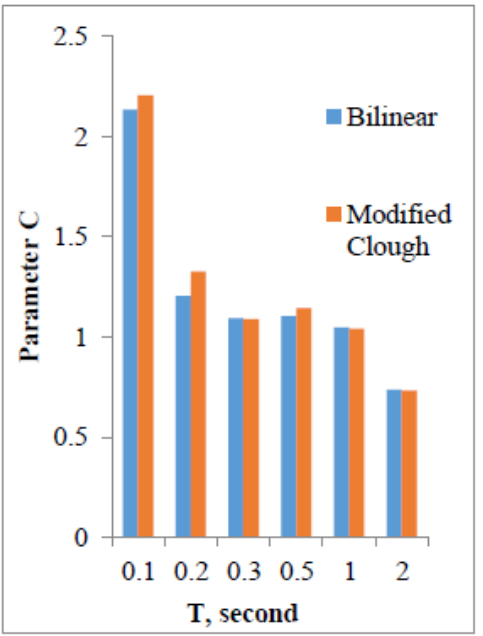

(c)

Fig. 11. Values of parameter $\mathrm{C}$ for bilinear and modified Clough models at $0.05,0.1$ and 0.2 post yielding stiffness ratios, (a) PY 5\%, (b) PY $10 \%$, (c) PY $20 \%$

Table 2. Values of parameter $\mathrm{C}$ for bilinear model

\begin{tabular}{lllll}
\hline Period & Post yielding stiffness ratio & & \\
(sec.) & 0 & 0.05 & 0.1 & 0.2 \\
\hline 0.1 & 3.044 & 2.485 & 2.294 & 2.029 \\
0.2 & 1.464 & 1.369 & 1.251 & 1.172 \\
0.3 & 1.525 & 1.330 & 1.167 & 1.015 \\
0.5 & 1.105 & 1.031 & 1.097 & 0.987 \\
1 & 1.003 & 0.997 & 1.015 & 1.058 \\
2 & 0.845 & 0.695 & 0.735 & 0.748 \\
\hline
\end{tabular}

Table 3. Values of parameter $\mathrm{C}$ for modified clough model

\begin{tabular}{llll}
\hline Period & Post yielding stiffness ratio & \\
(sec.) & -0.05 & 0.1 & 0.2 \\
\hline 0.1 & 2.703 & 2.413 & 2.064 \\
0.2 & 1.511 & 1.381 & 1.281 \\
0.3 & 1.472 & 1.235 & 0.994 \\
0.5 & 1.133 & 1.097 & 1.024 \\
1 & 1.097 & 1.024 & 1.050 \\
2 & 0.718 & 0.728 & 0.713 \\
\hline
\end{tabular}


Therefore, the bilinear model is not always the conservative solution for design while it requires lower demands than the modified Clough. Also, when the structural period increases the differences between Cvalues decreases which implies that rigid systems are more sensitive to hysteresis model type than flexible systems.

\section{Site Condition}

In this study, six synthetic records presenting two site conditions are investigated; hard rock and stiff soil site. C-values are evaluated and compared with (N\&K) model for both sites. The comparison between $\mathrm{C}$-values of each site and (N\&K) model with PY equals to $0 \%$ is shown in (Fig. 12 and 13), it can be

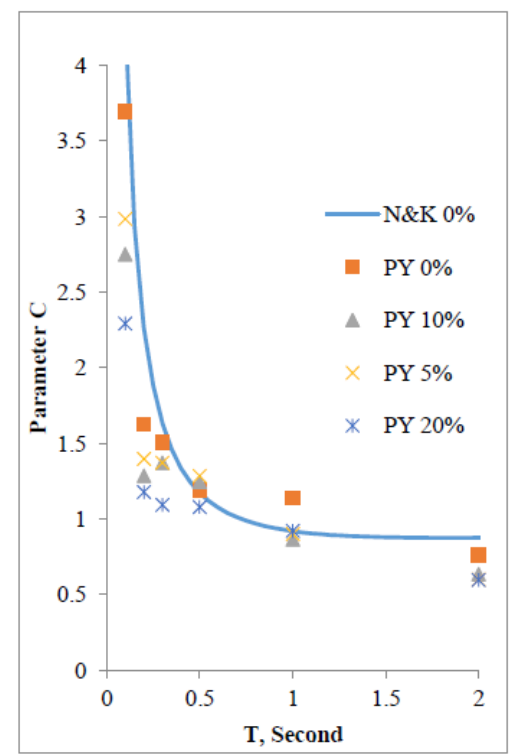

(a) noticed that despite of the soil condition, C-values follow the same trend.

However, in order to show the differences between both sites clearly, a percentage of difference of Cvalues from stiff soil to the hard rock is computed and plotted for both models and for all post yielding stiffness ratios; as presented in (Fig. 14), the positive ratio means that the $\mathrm{C}$-values of stiff soil sites are larger than hard rock sites, while the negative ratio means that the $\mathrm{C}$-values of stiff soil sites are smaller than hard rock sites. It was found that in short period the hard rock soils have greater spectral acceleration than the stiff soils and for long periods the stiff soils have a greater spectral acceleration than the hard rock soils.

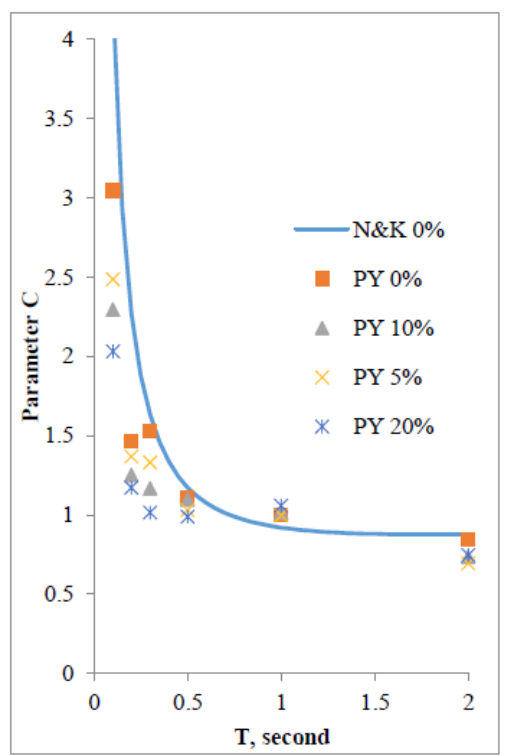

(b)

Fig. 12. Vas of parameter $\mathrm{C}$ for Bilinear model at different periods against N\&K model, (a) Stiff soil site, (b) Hard rock site

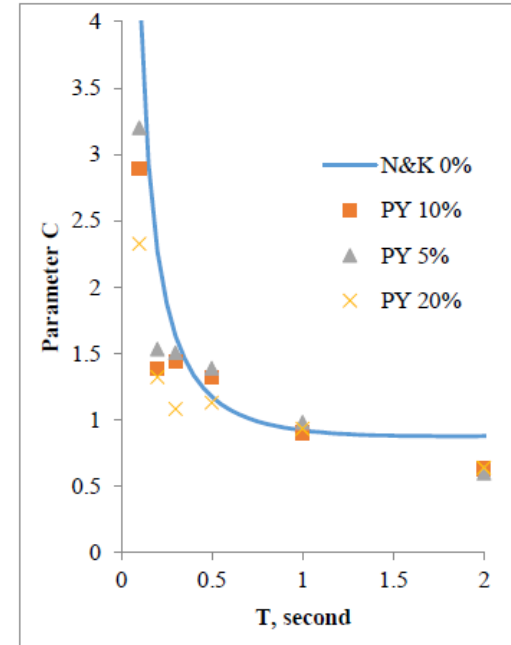

(a)

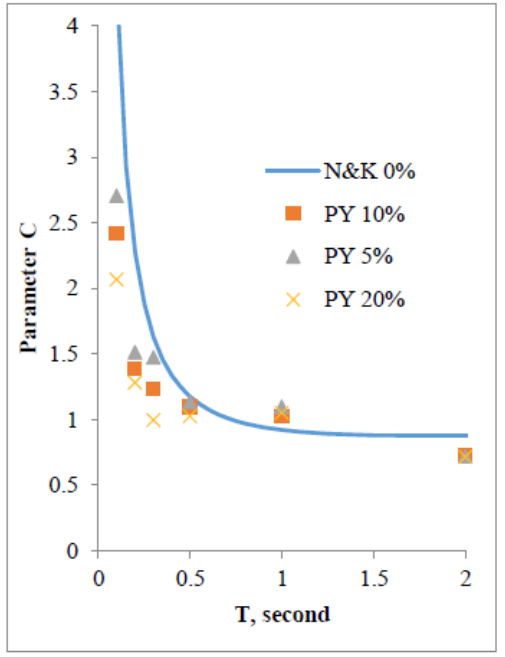

(b)

Fig. 13. Values of parameter $\mathrm{C}$ for modified clough model at different periods against N\&K model, (a) Stiff soil site (b) Hard rock site 


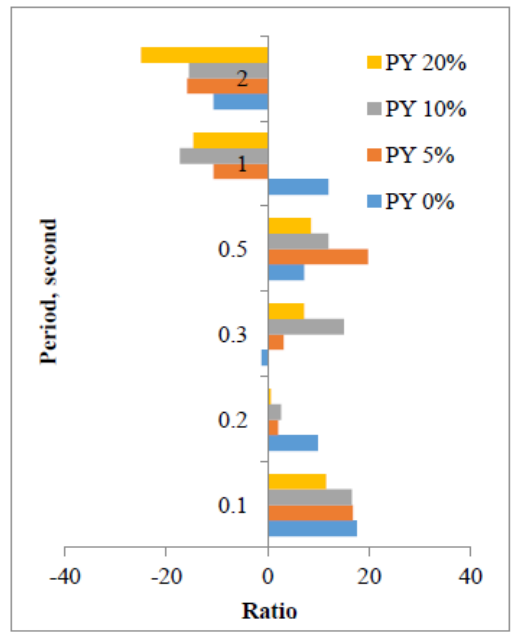

(a)

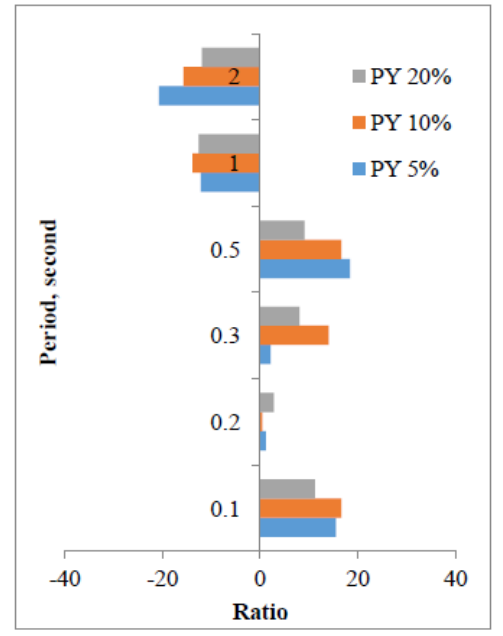

(b)

Fig. 14. Ratio of C-values between Stiff Soil sites to Hard Rock site for both models for all post yielding stiffness ratio, (a) Bilinear model, (b) Modified clough model

Therefore, to relate this with seismic demands of SDOF system ( $\mathrm{R}$ and $\mu$ ), it is important to illustrate the relationship between the spectral acceleration and the ductility demand ratio; while; when the spectral acceleration increases the ductility demand ratio decreases.

These results provide a clear distinction between the stiff soils and the hard rock, while it is observed that for short period systems, the stiff soil sites have larger $\mathrm{C}$-values which means higher ductility demand and lower spectral acceleration, since in long period systems the stiff soil sites have the smaller C-values which means lower ductility demand and higher spectral acceleration; therefore, the rock sites are critical case in flexible systems, while stiff soils are critical case in rigid systems regardless to the post yielding stiffness ratio and the type of the model.

\section{Conclusion}

The amount of reduction in the seismic design force mainly depends on the ductility demand of the structure and this relation is affected by many factors. A statistical study has been carried out to evaluate the effect of post yield stiffness ratio, structural period, hysteresis model and site condition on the relationship between the force modification factor and the ductility demand ratio. The following conclusions can be drawn from the results of this research.

Increasing the post yield stiffness ratio of a SDOF system will result in lower $C$ values based on (N\&K) model, which means that the ductility demand ratio is lower because of the increase of maximum restoring force and the reduction in the maximum inelastic displacement when the post yield stiffness ratio increases.

The modified Clough hysteresis models have higher $\mathrm{C}$ values than bilinear models due to the higher ductility demand; bilinear model is not always the conservative case for design. Also the effect of the type of hysteresis model is larger in the rigid systems in comparison with flexible systems.

$\mathrm{C}$-values in short period systems are higher than in long period systems regardless of the parameter variation, because the ductility demand for short period system is higher than long period structures.

The C-values for the hard rock at long period systems are higher than the stiff soil systems and the C-values for the stiff soil at long period systems are higher than the hard rock systems for short period systems, despite of any parameter variation. This is due to the higher spectral acceleration of stiff soils in long period systems and lower spectral acceleration of stiff soils in short period.

Generally, the C-values in this study are slightly lower than the (N\&K) model regardless the post yielding stiffness ratio, due to different earthquake records; synthetic records.

The effect of each parameter on the seismic demands is independent.

\section{Funding Information}

The authors have no support or funding to report.

\section{Author's Contributions}

Ahmad Tarawneh and Sereen Majdalaweyh: Organized research plan, conducting the analysis, discussion and contributed in the writing of the manuscript.

Bassam Mahasneh: Provided technical consultancy about manuscript writing, numerical analyses and discussions. 


\section{Ethics}

Author declares that there are not ethical issues that may arise after the publication of this manuscript.

\section{References}

Clough, W., 1966. Effect of Stiffness Degradation on Earthquake Ductility Requirements. 1st Edn., University of California, Berkeley, pp: 134.

MATLAB R2012a, 2012. MathWorks.

Miranda, E., 2004. Inealstic displacement ratios for structures on firm sites. J. Struct. Eng., 126: 1150-1159. DOI: 10.1061/(ASCE)07339445(2004)130:12(2051)

Nassar, A. and H. Krawinkler, 1991. Seismic demands for SDOF and MDOF systems. Stanford University, USA.
Ruiz-Garcia, J. and E. Miranda, 2005. Inelastic displacement ratios for structures built on soft soil sites. J. Struct. Eng., 130: 2051-2061.

DOI: 10.1061/(ASCE)0733-445(2004)130:12(2051)

Riddell, R. and M. Newmark, 1979. Statistical Analysis of the Response of Nonlinear Systems Subjected to Earthquakes. 1st Edn., University of Illinois at Urbana-Champaign, Urbana, pp: 582.

Veletsos, S. and M. Newmark, 1960. Effect of inelastic behavior on the response of simple systems to earthquake motions. Proceeding of the 2nd World Conference Earthquake Engineering, Jul. 11-18, Tokyo, Japan, pp: 895-912. 